\title{
Deeper Learning - How can it revolutionize African education and pre- pare students for the future workforce?
}

\author{
AMBALIKA DOGRA \\ Principal SRMCOE \\ ambalika.at.research@gmail.com
}

\begin{abstract}
The term 'Deep learning' is widespread today from the name of machine learning. On the contrary, another term 'Deeper Learning' from the area of education was prevalent a decade ago, but now it is becoming a fashionable phrase for educationists. It is not just a buzz word, but it also has a power to change the status quo of education and revamp it to the next level. Though, it has the potential to transform teaching and learning, it is still unsure how to gear it up in education and perhaps, a stronger and a new pedagogy is much needed here to usher into fourth industrial revolution.

The purpose of this perspective paper is to find out and design a new pedagogical framework which can be utilized to carry out the process of deeper learning and prepare students for the future workforce. The chief mission is to improve deeper learning skills of students, and to make it, author decided to bring a new design for deeper learning. Executed with a 21 st century pedagogy, deeper learning is the most effective approach to achieve and improve learning process of students and turn them into learning leaders instead of focusing more on their academic outcomes. The priority is to improve meaningful learning and its application. Application means transferring what one has learned into another situation which can be similar or completely dissimilar. However, before transferring, it is significant to have a meaningful learning, only then transfer can take place. This paper has emphasized on a new pedagogy which can improve the learning process of students through the use of digital technology.
\end{abstract}


Because of the scarcity of research on deeper learning, author has analyzed deeper learning talk or articles, and determined to lead a new DL (deeper learning) Framework. Evidences were gathered concerning what researchers and schools are doing along with authors' own perspective to bring deeper learning in teaching and learning, then a new pedagogical framework was brought out.

This perspective has great implications to improve deeper learning skills of students. Schools, College or Universities can use DL framework as a reference on how to use deeper learning approach in education.

\section{INTRODUCTION}

There is a soaring low enrollment rate of children, adolescents and youth specifically in Sub-Saharan part of Africa where 1/5th of the children between the age 6 and 11 do not go to school, whereas 1/3rd of students between 12 and 14 years of age do not opt for school. On the other hand, $60 \%$ of the youth between the age range 15 and 17 do not prefer school (UNESCO, 2018). Besides Africa, 236 million of children and youth are out of school in a world. The director of UNESCO Institute of Statistics (UNESCO, 2018) states there is a crisis in the learning as well. She insisted we need to have the effective monitoring system to make sure that students stay in school and they are learning what they need to know. It indicates there is a problem in learning also as children or youth are not learning what they need to know. So, they do not possess skills required to work for the companies, and thus, not prepared for the future workforce.

\section{What is a future workforce?}

The future work is more about working and creating together; millions of people access Wikipedia on a regular basis, they collaborate and create with a full freedom, working through collective wisdom, and become lifelong learners. Earlier, educators focused on imbibing reading, writing, and arithmetic, but nowadays, companies are looking for four C's (collaboration, communication, critical thinking, creativity). The National Network of Business and 
Industry Associations (2015) devised future "employability skills" categorized into "personal, people, applied knowledge, and workplace skills". Many deeper learning competencies are common with these employability skills: integrity, initiative, adaptability, professionalism (personal skills); teamwork, communication (people skills); reading, writing, mathematics, science, technology, critical thinking (applied knowledge); planning, organizing, problem solving, working with tools and technology (workplace skills). Adding to it, World Economic Forum (January, 2016) argued that social and collaboration skills shall be in an inflated demand than technical skills by 2020 .

However, the question is if we are really instilling these skills? Much of our classrooms are still based upon chalk and board method, and a change brought up by a revolution of robotics and artificial intelligence has dwindled the future jobs because our present generation do not possess those skills required to work in such a revolution. A new policy is needed which can develop deeper learning competencies. The ongoing education policy presents a new challenge of how to inculcate and measure these competencies because current assessment predominantly focus on recalling knowledge than its application (Pellegrino \& Hilton, 2012), and increases the space between learners' abilities and challenges of an emerging economy.

\section{Deeper Learning}

The idea of deeper learning is not new, but the term is a new buzz in the era of digital technology. Earlier, Ausubel (2000) proposed meaningful learning, and echoed that humans learn by connecting previous knowledge with the new one: meaningful learning as opposed to rote memorization is one of the attribute of deeper learning. Thorndike and Woodworth (1901) proved that learning is dependent on the previous experience; they proposed "transfer of practice effect" where they insisted that learning is transferred if the elements in both situations are similar. Transferring what we have learned in one situation and applying to another situation is a characteristic of deeper learning. 
Educators have always contemplated deeper learning as learning something deeply which means acquiring rigorous and deep academic content. However, nowadays it is contrasted with $21 \mathrm{st}$ century skills: collaboration, critical thinking, problem solving, creativity, communication, academic mindset, and learning how to learn. Also, Bellanca (2015) argued that deeper learning is both process and an outcome. It is a process in which new skills are gained by learners, they get new attributes, and an outcome when they transfer their learning to a novel situation to solve problems by employing these skills. Instilling new skills among learners are must for them to thrive in the fourth industrial revolution.

Deeper learning entails three significant elements: self-directed meaningful learning, adapting oneself to the new situation, and transferring it not only to the similar academic situations, but to other real-life problems or to the world, thus transforming learners to a digital or a global citizen who can work effectively anywhere in the world.

\section{How to prepare students for the future workforce?}

Deeper learning entails that learners apply what they have learned to resolve novice problems by exhibiting deeper learning competencies such as collaboration, communication, critical thinking, learning how to learn and academic mindset. American Institute of Research (2016) echoed that students who attended schools worked on developing deeper learning competencies experienced improved outcomes than students who did not attend such schools. Project-based learning, internship programs, study groups, group work and long-term assessment strategies have been effectively used by network schools to improve deeper learning competencies of their students (American Institute of Research, 2014). Apart from these strategies, one important way is to transform learners from knowledge receivers to knowledge creators, engage them with learning, enhance their level of metacognition, transform them from listener to a complete owner, creator, or innovator and a learning leader. 
We need a clear roadmap to prepare students for deeper learning:

1. Imbibe deeper learning skills required to work in a 21 st century.

2. 21 st century pedagogy to inculcate these skills.

3. Use of digital technology.

The first thing comes to mind for inculcating deeper learning skills is to change mindset of students from fixed to a growing one. As per Dweck (2007), growth mindset assumes that intelligence can be developed; people having growth mindset embrace challenges, do not give up early during obstacles, and learn from criticism.

Secondly, a concoction of strong pedagogical framework and digital technology can bring fruitful results. There are many ways to improve learners' deeper learning or 21st century skills in a digital world- its new pedagogical framework is explained with the help of following figure 1.1 and 1.2:

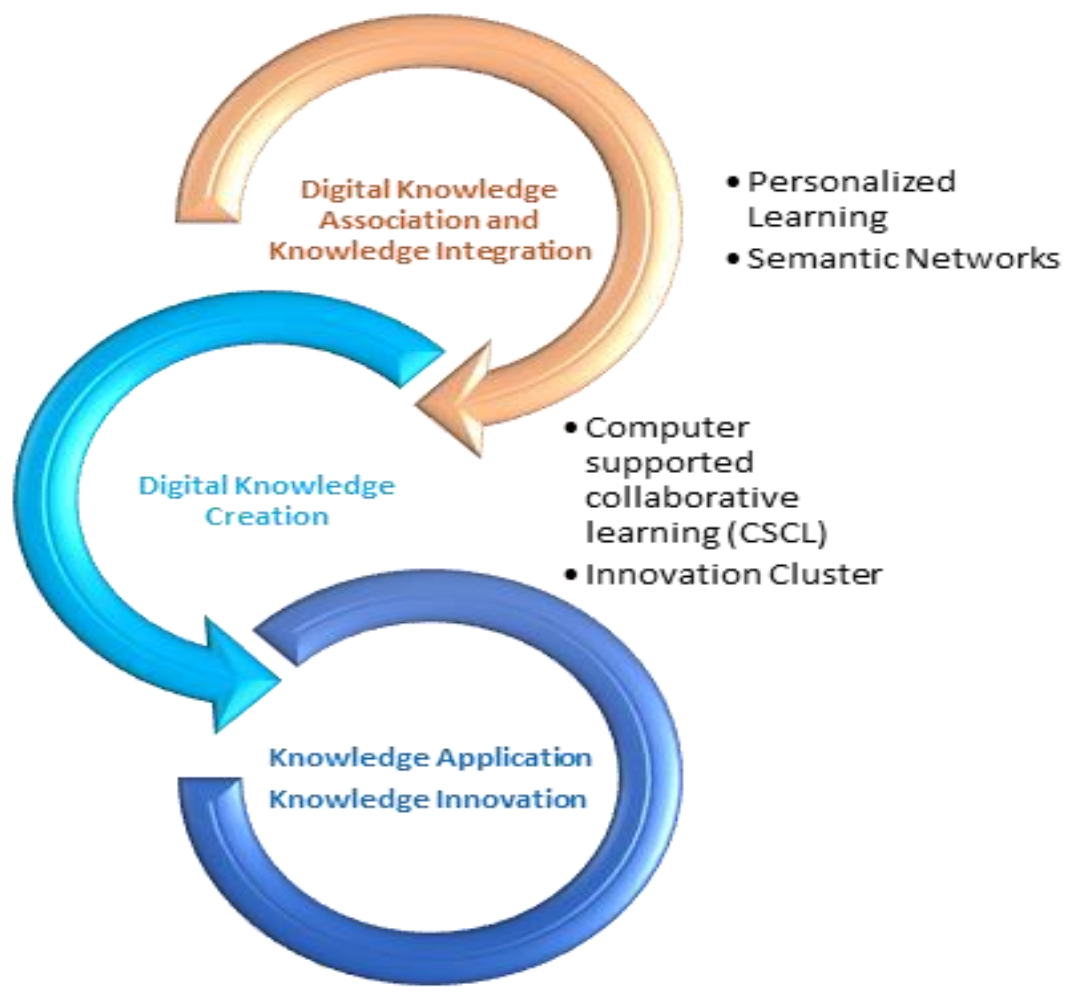

$1.121^{\text {st }}$ Century Pedagogical or DL Framework 


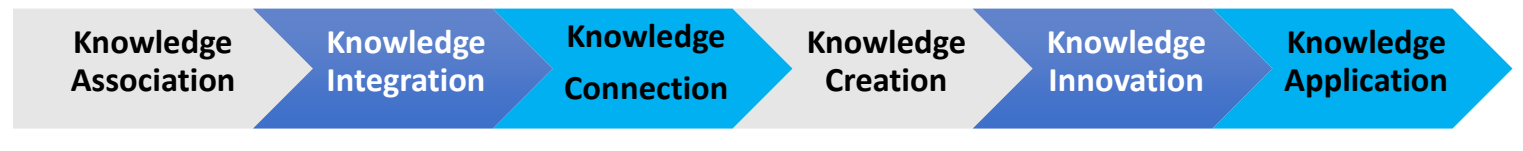

\subsection{Scale of $21^{\text {st }}$ century or DL Pedagogy}

The global society is driven by creativity and innovation rather than a discovery, so the new pedagogical framework is about digital knowledge association and knowledge creation. According to this pedagogy, knowledge is not discovered, in fact it is created through the help of other people and digital technology. It is explained under the subsequent points:

Firstly, students need to comprehend their learning process and they must act like a learning leader to enhance their learning leadership. Since, every individual is different, and thus possess distinct capacity to learn and follows typical learning process or a pathway; individualized or personalized instructions act as an asset to begin this task. Besides, technology can also create a great personal learning environment; It helps educators to develop individual learning pathway for each learner. In a survey by Pilley (2016), it was observed that $89 \%$ elementary educators and principals from "Southwest Missouri school district" believed that the execution of personalized learning has become simplified because of the technology. One of the example is School of One which provides personal learning to school students by leveraging digital technology where personal plans are created by retrieving students' data, and educators are informed about the performance of their students through furnishing them with 'real-time data'.

Hence, a blend of personalized learning and semantic network may assist students in knowledge association and integration which is the first component of 21 st century pedagogy and explained under the subsequent sub-headings: 
1. Digital Knowledge Association and Integration: The fundamental aim of every educator or learner is to learn something meaningfully, understand it to a deeper level. Besides, it has always been echoed by researchers that concepts do no exit individually, but they make associations with the related concepts, and that's how humans learn. We make connections of the interrelated concepts, and it helps us to learn and comprehend it. To learn meaningfully, we need to associate knowledge with our past experiences, and Semantic networks may help a lot in this regard. There are many ways and strategies employed to improve the process of learning, and one of them is to link new information with the existing one to help learners in acquiring a new concept. The existing information indicates, a knowledge, learner has earned from one's past experiences whether in school, with teachers, peers or family. Learning and personal experience has a positive relation, and David Ausubel, an American psychologist, stressed upon the link of past experiences with the learning and implied that people learn from experiences because they are stored in the memory, and there is a link between past and new knowledge we gain. Owing to the fact, we have our own personal experiences, hence, each one of us possess distinct cognitive structure and therefore, we follow different learning path or process for receiving any information. Everyone has a different capacity to organize relationship between ideas in their memory, and organization or representation of these ideas form a network termed as Semantic Network. Each learner need to know his or her semantic network for the concept and teachers can match their semantic network with them to determine the level of knowledge learners hold in their possession. Relating new knowledge with the past one strengthens one's cognitive structure, and it becomes easy for a learner to grasp new concepts which improves their learning process, and it leads to meaningful learning.

Semantic network is a technique which helps in knowledge representation and engross learners in analyzing the structure of knowledge they have and organize existing ideas with the new ones to represent knowledge, which in turn enhances critical thinking and higher order learning skill of learners. Semantic 
networking processes knowledge to the deeper level, and thus helps in reorganizing knowledge by mapping the content knowledge onto the cognitive structure of learners (Gulmans, 2004).

2. Digital Knowledge Connection and Creation: After understanding the concept to the deeper level, and associating it with the past experiences, learners create new knowledge. They connect with other learners not only from the same class or course, but from other courses, schools, and universities. Knowledge creation pedagogy is best to prepare students for 21 st century. How this knowledge creation pedagogy is applied?

Learners connect with their peers, teachers, and then collaborate through computer supported collaborative learning to create a knowledge on the topic or recent problem associated with the topic. Innovation cluster may be formed by engaging students with students from the same course, global students of the same course, educators, researchers and entrepreneurs. This innovation cluster is based upon knowledge creation pedagogy where creation and then innovation happens. This pedagogy echoes that knowledge is created, but not discovered; what students contribute to the society or community is primarily focused than what at an individual level they know or what's in their mind. Hence, it goes from knowledge creation or building a knowledge creation society to the one which is innovation driven.

This new framework, a concoction of new pedagogy and digital technology improves many global 21st century skills of students: personalized learning and semantic networks assist students in providing a meaningful learning where critical thinking and learning leadership skills of students are developed. It helps them to explore their personal process or path of learning; makes a strong academic foundation (academic mindset) for students and make them capable to lead towards knowledge creation. Also, it improves their initiative and self-direction capability. Besides, innovation cluster, and 
computer supported collaboration improves their interpersonal skill, collaboration, critical thinking, social and cross-cultural interaction and prepare them to work in diverse teams and turn them into a global or digital citizen.

\section{Conclusion}

This paper has echoed from the perspective of deeper learning as it is considered as a fourth educational revolution. Everyone is talking about preparing students for the fourth industrial revolution whether educational technology companies or education researchers, but the need of an hour is to build a new pedagogy where co-creation and application is more emphasized than recalling the facts. Author has brought the focus on associating and integrating knowledge with the previous experience and making a network of concepts before creation and application. Application means transferring knowledge to another situation, however, to transfer it, one needs to have a meaningful learning. Meaningful learning stresses more on association of facts than recalling them which improves understanding. The new scale of pedagogy begins from associating and integrating concepts with the past experiences and help students to make their thinking and knowledge more visual and explicit. Semantic network can be utilized to achieve it. After understanding one's own individual learning pathway or a process through semantic network, students connect with other peer and experts, then co-create and co-innovate by utilizing collaborative computer supported learning and innovation cluster. 


\section{References}

[1] American Institute for Research (September, 2014). Does deeper learning improve student outcomes? Retrieved from http://www.air.org/project/study-deeper-learning-opportunities-and-outcomes

[2] American Institute for Research (August, 2016). Does deeper learning improve student outcomes? Retrieved from http://www.air.org/project/study-deeper-learning-opportunities-and-outcomes

[3] Ausubel, D. P. (2000). Chapter 1: Preview of assimilation theory of meaningful learning and retention. The acquisition and retention of knowledge: a cognitive view. Springer Science + Business Media Dordrecht. Retrieved from http://www.springer.com/in/book/9780792365051?cm_mmc=sgw-_-ps-_-book-_-0-7923-6505-4

[4] Bellanca, J. A. (2015). Deeper Learning: Beyond 21st century skills. Solution Tree press: Bloomington, IN, USA. Retrieved from https://books.google.co.in/books?id=DY27BgAAQBAJ\&printsec=frontcover\&dq=deeper+learning $\& \mathrm{hl}=\mathrm{en} \& \mathrm{sa}=\mathrm{X} \&$ redir_esc $=\mathrm{y} \% 20-\% 20 \mathrm{v}=$ onepage $\& \mathrm{q}=\mathrm{deeper} \% 201$ earning $\& \mathrm{f}=\mathrm{false} \# \mathrm{v}=$ snippet\&q $=$ deeper\%20learning $\& \mathrm{f}=$ false

[5] Dweck, C. S. (2007). Mindset: the new psychology of success. Retrieved from https://www.amazon.in/Mindset-Psychology-Carol-S-Dweck/dp/0345472322?_encoding=UTF8\&portal-deviceattributes $=$ desktop $\&$ tag $=$ petewilloe $8-21$

[6] Gulmans, J. (2004). Mapping for the constructivistic acquisition of concepts? In P.A.M Kommers (Ed.) Cognitive Support for Learning: Imagining the Unknown. IOS Press, Amsterdam, The Netherlands. Retrieved from https://books.google.co.in/books?id=gbIApTr4viYC\&pg=PA45\&dq=Gulmans,,+ J.+(2004).+Cognitive+support+for+learning:+Imagining + the + unknown\&hl $=$ en $\& s a=X \&$ redir_esc $=y \% 20-\% 20 v=$ onepage $\& q=\mathrm{Gul}-$ mans\%2C\%20J.\%20(2004).\%20Cognitive\%20support\%20for\%20learning\%3A\%20Imagining\%20the\%20unknown\& $\mathrm{f}=$ false $\mathrm{v}=$ =nepage \&q=Gulmans\%2C\%20J.\%20(2004).\%20Cognitive\%20support $\% 20$ for\%20learning\%3A\%20Imagining\%20the \%20unknown\&f=false

[7] National Network of Business and Industry Associations (March, 2015). Common employability skills. Retrieved from http://www.nationalnetwork.org/wp-content/uploads/2015/03/Common_Employability_Skills-03-30-15.pdf

[8] Pellegrino, J. W. and Hilton, M. L. (2012). Education for life and work: developing transferable knowledge and skills in the 21st century [pre-publication copy]. National Academic Press: Washington, D.C. Retrieved from 
https://books.google.co.in/books?id=XsqDHRSo4NcC\&printsec=frontcover\&dq=deeper+learning\&hl=en\&sa $=X \&$ redir_esc $=\mathrm{y} \% 20-\% 20 \mathrm{v}=$ onepage $\& \mathrm{q}=$ deeper $\% 20$ learning $\& \mathrm{f}=$ false $\# \mathrm{v}=$ snippet\&q $=$ deeper $\% 201$ earning $\& \mathrm{f}=$ false

[9] Pilley, A. J. (2016). The role of technology in personalized learning and the effect on student achievement (Doctoral dissertation). Retrieved from ProQuest Dissertations and Theses database. (AAT 10174302)

[10] School of One (n.d.). Overview. Retrieved from http://izonenyc.org/initiatives/school-ofone/

[11] 11.UNESCO (2018). Education in Africa. Retrieved from http://uis.unesco.org/en/topic/education-africa

[12] 12.Woodworth, R. S., \& Thorndike, E. L. (1901). The influence of improvement in one mental function upon the efficiency of other functions. (I). Psychological Review, 8(3), 247-261.

[13] http://dx.doi.org/10.1037/h0074898

[14] 13. World Economic Forum (January, 2016). The future of Jobs. Retrieved from http://www3.weforum.org/docs/WEF_FOJ_Executive_Summary_Jobs.pdf 